\title{
Minimally-invasive versus open enucleation for pancreatic tumours: A propensity-score adjusted analysis
}

\author{
Tousif Kabir ${ }^{1}$, Zoe Z. X. Tan ${ }^{1}$, Nicholas Syn ${ }^{1,2}$, Alexander Y. F. Chung ${ }^{1,3}$, \\ London L. P. J. Ooi ${ }^{1,3}$, and Brian K. P. Goh ${ }^{1,3}$ \\ ${ }^{1}$ Department of Hepatopancreatobiliary and Transplant Surgery, Singapore General Hospital, \\ ${ }^{2}$ Yong Loo Lin School of Medicine, ${ }^{3}$ Duke NUS Medical School, Singapore
}

\begin{abstract}
Backgrounds/Aims: This study aims to evaluate the perioperative outcomes of minimally-invasive enucleation (MIEn) of the pancreas versus open enucleation (OEn). Methods: This is a retrospective review of 20 consecutive patients who underwent pancreatic enucleation at a single institution. Results: Seven patients underwent MIEn, of which 3 were robotic and 4 were laparoscopic. After propensity-adjusted analysis, the only significant difference was a reduced rate of readmissions within 30 days in the MIEn group versus the OEn group [0 vs $4(30.8 \%), p=0.0464$ ]. There were no conversions to open in the MIEn group, and median operation time was similar in both groups. There was no difference in median EBL in both groups, and none of the patients in our series required blood transfusions. The overall morbidity rate was $45.0 \%$ and the major complication (Clavien-Dindo $>2$ ) rate was $15 \%$; which was similar between both groups. Seven (35\%) patients had a Grade B/C POPF, and there was no significant difference between the two groups for this. The MIEn group had a shorter median length of stay compared to OEn [5 days (range, 3-24) vs 8.5 days (range, $5-42)]$ this was not significant on propensity-adjusted analysis $(p=0.3195)$. There was no post-operative 90 -day/ in-hospital mortality in all 20 patients. Conclusions: Our experience demonstrates that MIEn was associated with similar perioperative outcomes and fewer readmissions compared to OEn. (Ann Hepatobiliary Pancreat Surg 2019;23:258-264)
\end{abstract}

Key Words: Enucleation; Laparoscopic; Robotic; Minimally-invasive; Pancreas

\section{INTRODUCTION}

The conventional approach to resect pancreatic neoplasms has been to perform pancreaticoduodenenctomy (PD) for right-sided (head/uncinate) lesions and distal/ subtotal pancreatectomy for left-sided (body/tail) lesions. These are radical procedures with high morbidity, and often result in exocrine and endocrine insufficiency due to the large amount of tissue resected. ${ }^{1}$ In recent years, enucleation has become popular as an alternative strategy for low-grade pancreatic tumours such as pancreatic neuroendocrine tumors and cystic neoplasms. ${ }^{2}$

Advocates of this cite the preservation of pancreatic parenchyma as advantageous in reducing pancreatic insufficiency in the long term, ${ }^{3}$ while opponents are concerned about a possible higher rate of post-operative pancreatic fistula (POPF) following enucleation. ${ }^{4,5}$ As this procedure is selectively performed for tumours with low malignant potential, it is ideal for the minimally invasive approach, using either laparoscopy or robotic assistance via the Da Vinci $^{\circledR}$ Surgical System.

However, the safety and efficiency of this technique remains uncertain as there are few studies comparing open, laparoscopic and robotic enucleations. In this study, we aimed to evaluate the role of minimally invasive enucleation (MIEn) by comparing perioperative outcomes with the conventional open approach. Propensity score adjustment was performed to mitigate selection bias.

\section{MATERIALS AND METHODS}

We performed a retrospective review of all patients who underwent enucleation of pancreatic neoplasms in Singapore General Hospital from 1998 to 2018. This

Received: December 31, 2018; Revised: February 10, 2019; Accepted: February 21, 2019

Corresponding author: Brian K. P. Goh

Department of Hepatopancreatobiliary and Transplant Surgery, Singapore General Hospital, 20 College Road, 169856, 546149 Singapore Tel: +65-98156448, Fax: +65-98156448, E-mail: bsgkp@hotmail.com

Copyright (C) 2019 by The Korean Association of Hepato-Biliary-Pancreatic Surgery

This is an Open Access article distributed under the terms of the Creative Commons Attribution Non-Commercial License (http://creativecommons.org/ licenses/by-nc/4.0) which permits unrestricted non-commercial use, distribution, and reproduction in any medium, provided the original work is properly cited. Annals of Hepato-Biliary-Pancreatic Surgery • pISSN: 2508-5778 - elSSN: 2508-5859 
study was approved by our institution review board. Patients were classified into two groups based on intended initial approach, open enucleation (OEn) or MIEn. Decision to perform MIEn or OEn was based on an individual surgeon's decision after discussion with and obtaining informed consent from the patient. This was not based on any formalized institution protocol.

Data collected for comparison were the patient baseline demographics, intra-operative variables, post-operative outcomes, pathologic findings and long-term follow-up. Surgical data were collected from a prospective computerized database (OTM 10, IBM, Armonk, New York), whereas clinical data were collected from another prospective computerized clinical database (Sunrise Clinical Manager version 5.8, Eclipsys Corporation, Atlanta, Georgia).

\section{Definitions}

Pancreatic fistula (PF) was defined and graded according to the latest 2016 update by the International Study Group on Pancreatic Fistula. ${ }^{6}$ In this study, asymptomatic purely biochemical Grade A pancreatic fistulas were reported but were not considered a morbidity according to the latest definition. Postoperative morbidity was graded using the Clavien-Dindo classification ${ }^{7}$ as minor (Grade I/II) or major (Grade III-V), and recorded for up to 30 days or during the same hospital stay of surgery. Mortality was recorded up to 90 days from surgery or during the same hospital stay. MIEn included all patients who underwent an attempted pure laparoscopic or pure robotic enucleation. An open conversion was defined as when a resection initially attempted laparoscopically or robotically but required an open incision to complete the surgery.

\section{Operative technique}

The choice of operative technique, trocar placements and type of instruments used was based mainly on the surgeon's and patient's preference. For laparoscopic enucleation, patients were positioned supine with or without the legs apart. The operating table was placed in the reverse Trendelenburg position, with the left shoulder elevated if the lesion was left-sided. The surgeon and the camera holder stood on the patient's right side, while the first assistant stood on the left. An initial $10 \mathrm{~mm}$ camera port was placed in the supra-umbilical position, and diagnostic laparoscopy was performed to rule out metastatic disease. Subsequently, working ports were inserted in the right flank, right upper quadrant and left flank in a semi-circular manner.

The lesser sac was accessed by dividing the gastrocolic ligament using either a Harmonic scalpel (Harmonic Ace, Ethicon Endo-Surgery, Cincinnati, OH, USA), Ligasure (Covidien, Boulder, CO, USA) or Thunderbeat (Olympus, Tokyo, Japan). For tumors located in the head, the gastroepiploic vessels were frequently divided. The duodenum was kocherised and mobilized as needed. The neoplasm was identified visually or using intra-operative ultrasonography. Subsequently, the neoplasm was dissected off the pancreatic parenchyma, taking care not to injure the main pancreatic duct. Specimens were bagged and retrieved, and closed-suction drainage tubes were placed close to the resection site.

Robotic enucleation was performed using the Da Vinci ${ }^{\circledR}$ Si Surgical System (Intuitive Surgical, Sunnyvale, California, USA). The steps of the surgery were similar to those described above. Tumour enucleation and hemostasis was performed using a combination of monopolar hook, ultrasonic shears and bipolar forceps, with robotic hand-sewn stitches when necessary.

Patients were positioned supine for open enucleations. An upper midline or left subcostal incision was used for access. Otherwise, surgery was performed in the usual fashion.

\section{Statistical analyses}

Mood's median test and the chi-square test were used to compare continuous and dichotomous variables respectively.

\section{Propensity score-adjustment}

Propensity scores were calculated through logistic regression modelling based on the following clinically-selected covariates: ASA status (1 vs [2 or 3]), tumor size, distal (body/tail) or proximal (head/uncinated) tumor location, and previous abdominal surgery. Missing baseline covariates were multiply-imputed $(\mathrm{M}=50)$ using multivariate chained equations with augmented logistic regression for dichotomous variables and predictive mean matching (3 nearest neighbors) for continuous variables, and imputed datasets were combined according to Rubin's 
rules. Calibration, goodness-of-fit and discrimination were assessed using the methods of Lemeshow and Hosmer and receiver operating curves. The final propensity-score model exhibited an area under the receiver operating curve of 0.7473 (Supplementary Fig. S1) and good calibration (Supplementary Fig. S2).

To minimize confounding, comparisons of perioperative outcomes between the MIEn and OEn groups were adjusted using the linear predictor (log odds) of the propensity-scores. Concomitant surgery was included as a covariate in multivariable regression if its inclusion did not result in significant variance inflation (uncentered variance inflation factor $>10$ ) or significantly reduce the model likelihood. PS-adjusted quantile and logistic regression were used to compare conditional medians and proportions.

\section{RESULTS}

Table 1 summarizes the baseline demographic characteristics of patients in both groups. A total of 20 patients underwent pancreatic enucleation during the study period, of which 7 (35\%) underwent MIEn (5 female, 2 male) while 13 (65\%) underwent OEn (7 female, 6 male). Of the 7 MIEn patients, 4 were performed via the laparoscopic approach while 3 were via robotic assistance. There were no significant differences in baseline demographics be- tween the 2 groups. The median age of patients was 43 years (range 28-64) in the MIEn group and 56 years (range 38-66) in the OEn group. Median BMI was 22.3 (range 17.2-33.1) in the MIEn group and 28.2 (range 23.9-30.1) in the OEn group. Patients in both groups had similar American Society of Anaesthesiologist (ASA) scores.

There were no significant differences between the two groups in terms of median tumour size or location (proximal versus distal pancreas). With regards to the tumour pathology, there were 2 cystic lesions (1 pancreatic cyst, 1 branch-duct intraductal papillary mucinous neoplasm (IPMN)) while the rest were solid lesions (11 insulinomas, 1 metastatic lesion to pancreas from renal cell carcinoma, 1 retroperitoneal schwannoma involving part of the pancreas and the rest were non-functioning pancreatic neuroendocrine tumours). 1 (14.3\%) patient in the MIEn group and $5(38.5 \%)$ patients in the OEn group had concomitant surgical procedures performed in addition to pancreatic enucleation. The patient in the MIEn group had a laparoscopic resection of a retroperitoneal tumour, while the additional procedures in the OEn group were spleen-preserving distal pancreatectomy, wedge resection of colorectal liver metastasis, radical nephrectomy, cholecystectomy and excision of a duodenal nodule. $6(30 \%)$ patients had previous abdominal surgery, of which $3(42.9 \%)$ were in the MIEn group and $3(23.1 \%)$ were in the OEn group.

Table 1. Comparison between the baseline characteristics of MIEn vs OEn

\begin{tabular}{|c|c|c|c|c|}
\hline Baseline characteristics & All enucleations $(n=20)$ & MIEn $(n=7)$ & OEn $(n=13)$ & $p$-value \\
\hline Female:Male & $12: 8$ & $5: 2$ & $7: 6$ & 0.4439 \\
\hline Median age (IQR), yrs & $53(35.5-66)$ & $43(28-64)$ & $56(38-66)$ & 0.6392 \\
\hline Median BMI (IQR), $\mathrm{kg} / \mathrm{m}^{2}$ & $26.4(20.9-30.1)$ & $22.3(17.2-33.1)$ & $28.2(23.85-30.1)$ & 0.7821 \\
\hline ASA, n/total no. (\%) & & & & 0.3886 \\
\hline 1 & $10 / 18(55.6)$ & $4 / 7(57.1)$ & $6 / 11(54.5)$ & \\
\hline 2 & $7 / 18(38.9)$ & $2 / 7(28.6)$ & $5 / 11(45.5)$ & \\
\hline 3 & $1 / 18(5.6)$ & $1 / 7(14.3)$ & $0 / 11(0.0)$ & \\
\hline Median tumor size (IQR), mm & $15(13-17)$ & $15(14-17)$ & $14.5(11.5-17.5)$ & 0.5959 \\
\hline Tumor location, n/total no. (\%) & & & & 0.4192 \\
\hline Proximal (head/uncinate) & $12 / 20(60.0)$ & $3 / 7(42.8)$ & $9 / 13(69.2)$ & \\
\hline Distal (body/tail) & $8 / 20(40.0)$ & $4 / 7(57.2)$ & $4 / 13(30.8)$ & \\
\hline Tumor type, n/total no. (\%) & & & & 0.6392 \\
\hline Solid/NET & $18 / 20(90.0)$ & $6 / 7(85.7)$ & $12 / 13(92.3)$ & \\
\hline Cystic & $2 / 20(10.0)$ & $1 / 7(14.3)$ & $1 / 13(7.7)$ & \\
\hline Concomitant surgery, n (\%) & $6 / 20(30.0)$ & $1 / 7(14.3)$ & $5 / 13(38.5)$ & 0.2605 \\
\hline Previous abdominal surgery, $\mathrm{n}(\%)$ & $6 / 20(30.0)$ & $3 / 7(42.9)$ & $3 / 13(23.1)$ & 0.3572 \\
\hline
\end{tabular}

ASA, American Society of Anaesthesiology; IQR, interquartile range; MIEn, minimally-invasive enucleation; NET, neuroendocrine tumor; OEn, open enucleation 
Table 2. Comparison between the perioperative outcomes of MIEn versus OEn

\begin{tabular}{lccccc}
\hline \multicolumn{1}{c}{ Outcome } & All enucleations (n=20) & MIEn (n=7) & OEn (n=13) & $p$-value $^{\dagger}$ & $p_{\text {-value }}^{\ddagger}$ \\
\hline Open conversion, n (\%) & NA & $0 / 7(0.0 \%)$ & NA & NA & NA \\
Median operation time (range), min & $160(45-375)$ & $212.5(45-375)$ & $160(45-315)$ & 0.735 & 0.2882 \\
Median blood loss (range), ml & $75(0-650)$ & $37.5(0-100)$ & $300(0-650)$ & 0.137 & 0.4262 \\
Intraoperative blood transfusion, n (\%) & 0 & 0 & 0 & NA & NA \\
Any complication, n/total no. (\%) & $9 / 20(45.0)$ & $4 / 7(57.1)$ & $5 / 13(38.5)$ & 0.4231 & 0.1758 \\
Major complication (> grade 2), n (\%) & $3 / 20(15.0)$ & $1 / 7(14.3)$ & $2 / 13(15.4)$ & 0.948 & 0.9956 \\
Grade B/C pancreatic fistula, n (\%) & $7 / 20(35.0)$ & $3 / 7(42.9)$ & $4 / 13(30.8)$ & 0.589 & 0.4412 \\
Intra-abdominal collections, n (\%) & $6 / 19(31.6)$ & $2 / 7(33.3)$ & $4 / 12(33.3)$ & 0.8295 & 0.7537 \\
Haemorrhage, n (\%) & 0 & 0 & 0 & NA & NA \\
Median days to start feed (range), D & $1(0-4)$ & $1(0-1)$ & $1(0-4)$ & 0.036 & 0.0420 \\
Median postoperative stay (range), D & $7(3-42)$ & $5(3-24)$ & $8.5(5-42)$ & 0.027 & 0.3195 \\
30-day readmission, n (\%) & $4 / 20(20.0)$ & $0 / 7(0.0)$ & $4 / 13(30.8)$ & 0.101 & $0.0464 *$ \\
\hline
\end{tabular}

\footnotetext{
${ }^{\dagger}$ Unadjusted $p$-values were obtained from Mood's median test and the chi-square test for medians and proportions respectively, ${ }^{\dagger}$ Adjusted $p$-values were obtained from quantile and logistic regression for conditional medians and proportions respectively, adjusted for propensity scores and concomitant surgery, ${ }^{*} p$-value for likelihood ratio test for adjusted difference between proportions, because $p$-value from logistic regression was not estimable

$\mathrm{D}$, day; MIEn, minimally-invasive enucleation; OEn, open enucleation
}

Table 2 compares the perioperative outcomes between the MIEn and the OEn groups. On propensity-adjusted analysis, the only significant difference was a reduced rate of readmissions within 30 days in the MIEn group ( 0 readmissions, $0 \%$ ) versus the OEn group (4 readmissions, $30.8 \%)(p=0.0464)$. There were no conversions to open in the MIEn group, and median operation time was similar in both groups. There was no difference in median estimated blood in both groups, and none of the patients in our series required blood transfusions. The overall morbidity rate was $45.0 \%$ and the major complication (ClavienDindo $>2$ ) rate was $15 \%$; this was similar across both groups. Seven (35\%) of our patients had a Grade B/C POPF (6 grade $\mathrm{B}$ and 1 grade $\mathrm{C}$ ), and there was no significant difference between the two groups. Of these, 1 patient underwent percutaneous drainage of intra-abdominal collection, 5 patients had their surgical drains left in-situ for 3-4 weeks, and 1 patient had persistent pancreatic duct leak which eventually required a subtotal pancreatectomy and splenectomy. The MIEn group had a shorter LOS of 5 days (range 3-24) as compared to 8.5 days (range $5-42)$ in the OEn group $(p=0.027)$, but on propensity-matched analysis this was not significant $(p=0.3195)$. There was no post-operative 90-day/ in-hospital mortality in all 20 patients.

\section{DISCUSSION}

Our study showed that MIEn was associated with similar rates of overall morbidity, major complication and clinically significant POPF compared to OEn, hence confirming the safety and feasibility of the minimally invasive approach for pancreatic enucleation. To the best of our knowledge, this is only the second study to date to attempt to mitigate selection bias by conducting a propensity score analysis. In our experience, MIEn was also associated with significantly reduced readmission rate compared to OEn after propensity-score adjustment. We had no readmissions in the MIEn group, and amongst the 4 readmissions in the OEn group, 2 were for pain related to the incision site. This reinforces the benefit of reduced surgical trauma from the minimally invasive approach.

Enucleation has been advocated as a method of limited pancreatic resection for a select group of patients with small, low-grade pancreatic neoplasms ${ }^{8,9}$ which are situated away from the main pancreatic duct and on the anterior surface of the pancreas. In a meta-analysis of 22 retrospective studies comprising of 1148 patients, pancreatic enucleation was associated with reduced rates of post-operative exocrine and endocrine insufficiency, as well as shorter duration of surgery, lower blood loss and shorter LOS. ${ }^{10}$ Furthermore, sensitivity analysis of high-volume studies (more than 20 enucleations and more than 4 per 


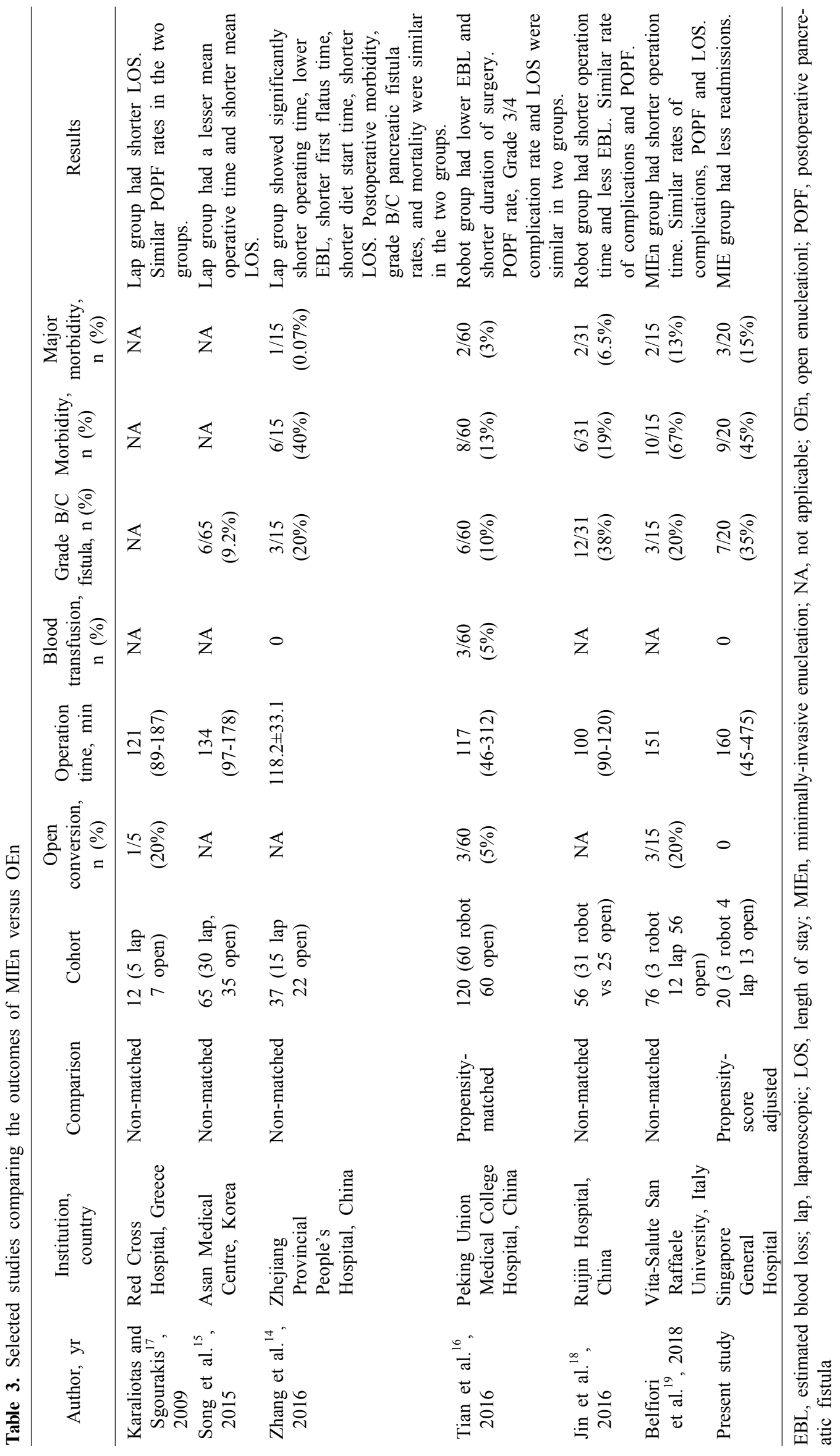


year) showed that in specialised centres, pancreatic enucleations can be performed with no increased risk of POPF. Enucleation has also been shown to have excellent short and long-term oncologic outcomes, with no increased risk of tumour recurrence. ${ }^{11,12}$ This may be partly explained by the fact that most tumours resected by enucleation were benign or had low malignant potential to begin with.

The first report of MIEn was a case of laparoscopic enucleation by Gagner et al. ${ }^{13}$ in 1996. Since then, there have been several comparative case series published in the literature comparing MIEn to OEn, as summarised in Table 3. ${ }^{14-19}$ Our institution has been performing minimally invasive pancreatectomies (MIP) for more than a decade, ${ }^{20}$ and our conversion rates following laparoscopic distal pancreatectomies are comparable to those of highvolume tertiary referral centres. ${ }^{21}$ We have also successfully performed robotic pancreatectomies, including PD and spleen-saving vessel preserving distal pancreatectomy. $^{22,23}$ Owing to the rarity of cases that are suitable for enucleation, the number of MIEn we have performed to date is relatively small. However, our outcomes are comparable nonetheless. Our vast experience over the years with both open and minimally-invasive pancreatectomies meant that our surgeons had surpassed their learning curves for MIP and were hence very comfortable performing MIEn. There were no conversions in the MIEn group. Median EBL in our MIEn group was lower than in the OEn group, in keeping with findings from other studies, ${ }^{24}$ although this was not statistically significant likely due to our small number of patients. The magnified view offered by the high-definition cameras in both laparoscopic and robotic surgery, the stable, tremor-free platform of the robot as well as the improved dexterity of the robotic Endowrist, allowed very precise dissection and meticulous hemostasis.

One key concern that surgeons have with performing enucleation is a potentially higher rate of POPF formation. $^{4}$ In our series, the overall rate of Grade B/C POPF was acceptably low, and was similar in the MIEn group as compared to the OEn group. These findings are concordant with several recent studies which have also reported no difference in the rates of clinically significant POPF between MIEn (both laparoscopic and robotic approach) and OEn. ${ }^{14-19}$
Although our operative time was slightly longer than that reported in most series, it is worthwhile to note that more than half of our enucleations were done for tumours in the proximal pancreas, as opposed to most studies where the majority of lesions were left-sided (body/tail). Right-sided dissection is known to be more challenging and therefore associated with longer operating times, as reported by Costi and Sahakyan. ${ }^{25-27}$

In the present study, the median LOS was significantly shorter for the MIEn group before propensity-score adjustment, concordant with the findings of previous studies. ${ }^{14,15,17}$ Interestingly, there was no significant difference after propensity-score adjustment, similar to the only other propensity-score matched study ${ }^{16}$ published to date comparing 60 robotic versus 60 open enucleations. This lack of difference in LOS between MIEn and OEn suggests that selection bias may have at least attribute to some of the differences observed in previous studies. The early recovery policy $^{28}$ adopted at our institution for all pancreatectomy patients and a Type 2 error due to our small sample size may have also contributed to this observation. These findings emphasize the importance of conducting a multi-institution prospective randomized control trial to determine the benefit of MIEn over OEn.

There are several limitations associated with this relatively small single center study. Firstly, due to its retrospective nature, it is subjected to selection bias. Secondly, the small sample size of the study renders it susceptible to both type 1 and type 2 errors. Finally, there was no long-term follow-up to determine functional outcomes, such as rates of endocrine and exocrine insufficiency following enucleation.

In conclusion, this study confirms that MIEn is feasible and safe, and is associated with similar perioperative outcomes and fewer readmissions compared to OEn.

\section{REFERENCES}

1. Kahl S, Malfertheiner P. Exocrine and endocrine pancreatic insufficiency after pancreatic surgery. Best Pract Res Clin Gastroenterol 2004;18:947-955.

2. Crippa S, Boninsegna L, Partelli S, Falconi M. Parenchyma-sparing resections for pancreatic neoplasms. J Hepatobiliary Pancreat Sci 2010;17:782-787.

3. Falconi M, Mantovani W, Crippa S, Mascetta G, Salvia R, Pederzoli P. Pancreatic insufficiency after different resections for benign tumours. Br J Surg 2008;95:85-91.

4. Strobel O, Cherrez A, Hinz U, Mayer P, Kaiser J, Fritz S, et 
al. Risk of pancreatic fistula after enucleation of pancreatic tumours. Br J Surg 2015;102:1258-1266.

5. Sperti C, Beltrame V, Milanetto AC, Moro M, Pedrazzoli S. Parenchyma-sparing pancreatectomies for benign or border-line tumors of the pancreas. World J Gastrointest Oncol 2010;2: 272-281.

6. Bassi C, Marchegiani G, Dervenis C, Sarr M, Abu Hilal M, Adham M, et al. The 2016 update of the International Study Group (ISGPS) definition and grading of postoperative pancreatic fistula: 11 years after. Surgery 2017;161:584-591.

7. Dindo D, Demartines N, Clavien PA. Classification of surgical complications: a new proposal with evaluation in a cohort of 6336 patients and results of a survey. Ann Surg 2004;240:205-213.

8. Crippa S, Bassi C, Salvia R, Falconi M, Butturini G, Pederzoli P. Enucleation of pancreatic neoplasms. Br J Surg 2007;94:12541259.

9. Kaiser J, Fritz S, Klauss M, Bergmann F, Hinz U, Strobel O, et al. Enucleation: a treatment alternative for branch duct intraductal papillary mucinous neoplasms. Surgery 2017;161:602-610.

10. Hüttner FJ, Koessler-Ebs J, Hackert T, Ulrich A, Büchler MW, Diener MK. Meta-analysis of surgical outcome after enucleation versus standard resection for pancreatic neoplasms. Br J Surg 2015;102:1026-1036.

11. Zhang T, Xu J, Wang T, Liao Q, Dai M, Zhao Y. Enucleation of pancreatic lesions: indications, outcomes, and risk factors for clinical pancreatic fistula. J Gastrointest Surg 2013;17:2099-2104.

12. Wang X, Tan CL, Zhang H, Chen YH, Yang M, Ke NW, et al. Short-term outcomes and risk factors for pancreatic fistula after pancreatic enucleation: a single-center experience of 142 patients. J Surg Oncol 2018;117:182-190.

13. Gagner M, Pomp A, Herrera MF. Early experience with laparoscopic resections of islet cell tumors. Surgery 1996;120:1051-1054.

14. Zhang RC, Zhou YC, Mou YP, Huang CJ, Jin WW, Yan JF, et al. Laparoscopic versus open enucleation for pancreatic neoplasms: clinical outcomes and pancreatic function analysis. Surg Endosc 2016;30:2657-2665.

15. Song KB, Kim SC, Hwang DW, Lee JH, Lee DJ, Lee JW, et al. Enucleation for benign or low-grade malignant lesions of the pancreas: single-center experience with 65 consecutive patients. Surgery 2015;158:1203-1210.

16. Tian F, Hong XF, Wu WM, Han XL, Wang MY, Cong L, et al. Propensity score-matched analysis of robotic versus open surgical enucleation for small pancreatic neuroendocrine tumours. Br J Surg 2016;103:1358-1364.
17. Karaliotas C, Sgourakis G. Laparoscopic versus open enucleation for solitary insulinoma in the body and tail of the pancreas. $\mathrm{J}$ Gastrointest Surg 2009;13:1869.

18. Jin JB, Qin K, Li H, Wu ZC, Zhan Q, Deng XX, et al. Robotic enucleation for benign or borderline tumours of the pancreas: a retrospective analysis and comparison from a high-volume centre in Asia. World J Surg 2016;40:3009-3020.

19. Belfiori G, Wiese D, Partelli S, Wächter S, Maurer E, Crippa $\mathrm{S}$, et al. Minimally invasive versus open treatment for benign sporadic insulinoma comparison of short-term and long-term outcomes. World J Surg 2018;42:3223-3230.

20. Goh BKP, Lee SY, Kam JH, Soh HL, Cheow PC, Chow PKH, et al. Evolution of minimally invasive distal pancreatectomies at a single institution. J Minim Access Surg 2018;14:140-145.

21. Goh BKP, Chan CY, Lee SY, Chan WH, Cheow PC, Chow $\mathrm{PKH}$, et al. Factors associated with and consequences of open conversion after laparoscopic distal pancreatectomy: initial experience at a single institution. ANZ J Surg 2017;87:E271-E275.

22. Goh BKP, Low TY, Lee SY, Chan CY, Chung AYF, Ooi LLPJ Initial experience with robotic pancreatic surgery in Singapore: single institution experience with 30 consecutive cases. ANZ J Surg 2019;89:206-210.

23. Goh BK, Wong JS, Chan CY, Cheow PC, Ooi LL, Chung AY. First experience with robotic spleen-saving, vessel-preserving distal pancreatectomy in Singapore: a report of three consecutive cases. Singapore Med J 2016;57:464-469.

24. Wang X, Chen YH, Tan CL, Zhang H, Xiong JJ, Chen HY, et al. Enucleation of pancreatic solid pseudopapillary neoplasm: shortterm and long-term outcomes from a 7-year large single-center experience. Eur J Surg Oncol 2018;44:644-650.

25. Costi R, Randone B, Mal F, Basato S, Lévard H, Gayet B. A critical appraisal of laparoscopic pancreatic enucleations: rightsided procedures (Pancreatic Head, Uncus) are not mini-invasive surgery. Surg Laparosc Endosc Percutan Tech 2013;23:524-531.

26. Sahakyan MA, Røsok BI, Kazaryan AM, Barkhatov L, Haugvik $\mathrm{SP}$, Fretland $\AA \mathrm{A}$, et al. Role of laparoscopic enucleation in the treatment of pancreatic lesions: case series and case-matched analysis. Surg Endosc 2017;31:2310-2316.

27. Di Benedetto F, Magistri P, Ballarin R, Tarantino G, Bartolini I, Bencini L, et al. Ultrasound-guided robotic enucleation of pancreatic neuroendocrine tumors. Surg Innov 2019;26:37-45.

28. Perinel J, Adham M. ERAS and pancreatic surgery: a review. Updates Surg 2016;68:253-255. 